\title{
ĐẶC ĐIỂM LÂM SÀNG, CẬN LÂM SÀNG CỦA BỆNH NHÂN NHIỄM KHUẨN HUYẾTDO KLEBSIELLA PNEUMONIAE
}

\author{
Nguyễn Lan Hương1, Thân Mạnh Hùng'², Lê Văn $\mathrm{Nam}^{3}$
}

\section{TÓM TẮT}

Mục tiêu: mô tả mô̂t số đăc điểm lâm sàng, cận lâm sàng ở bệnh nhân nhiễm khuẩn huyết do Klebsiella pneumoniae. Đối tượng và phương pháp: nghiên cứu mô tả, cắt ngang tiến cứu kết hợp hôi cứu trên 48 bệnh nhân nhiễm khuẩn huyết do Klebsiella Pneumoniae điều tri tai Bênh viên Quân y 103 (01/2017 đến 6/2021). Kết quả nghiên cứu: tuổi trung bình $62,67 \pm 12,66$ tuổi; $77,08 \%$ namgiới; $72,90 \%$ có bệnh lý nền; $10,40 \%$ là nhiềm khuẩn bệnh viên; $85,40 \%$ có xác định được đường vào (đường vào hổ hấp là cao nhất $41,46 \%$ ); $27,08 \%$ cân can thiêp thủ thuât trong quá trình nằm viên; thời gian nằm viển trung bình: $16,31 \pm 1,37$ ngày; $100 \%$ có sốt, bao gồm sốt đôt ngôt $100 \%$, sốt cao $45,80 \%$ và $58,30 \%$ có cơnrétrun; 60\%mạch > 90 chu kỳ/ phút,12,50\% có sốc; $61 \%$ có viêm phổi; $16,90 \%$ có suy hô hấp; bạch câu >12G/L: 43,80\%; Hb < 120g/l: 86,80\%; tiểu cầu < 150G/l: 39,50\%; PT\% < 70\%: 53,85\%; ure > 7,5mmol/L: 47,06\%; creatinine $\geq 110 \mu \mathrm{mol} / \mathrm{L}: 28,21 \%$;

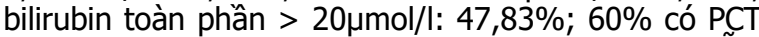
$>10 \mathrm{ng} / \mathrm{ml} ; 60 \%$ có CRP $>100 \mathrm{mg} / \mathrm{L}$. Kết luận: nhiếm khuấn huyết do $\mathrm{K}$. pneumoniae tỷ lệ cao đường vào từ đường hô hấp và tiêu hóa, rối loạn nhiều cơ quan, tỷ lệ shock nhiễm khuẩn và tử vong cao.

Tư khóa: nhiễm khuẩn huyết, Klebsiella pneumoniae; đặc điểm lâm sàng, cận lâm sàng.

\section{SUMMARY}

\section{CLINICAL MANIFESTATION AND}

\section{LABORATORY CHARACTERISTICS OF} KLEBSIELLA PNEUMONIAE SEPTICEMIA

Objectives: To describe some clinical and laboratory characteristics of Klebsiella pneumoniae septicemia. Subjects and methods: Descriptive, cross-sectional, prospective and retrospective study in 48 septicemia patients caused by Klebsiella pneumoniae admitted to 103 Military Hospital from January 2017 to June 2021. Results: Median age: $62.67 \pm 12.66$ years; male $77,08 \%$; underlying diseases: $72.90 \%$; $10.40 \%$ hospital infection; $85.40 \%$ identified the path to infection (from respiratory tract $41.46 \%) ; \quad 27.08 \%$ required surgical intervention during hospital stay; average hospital stay: $16.31 \pm 1.37$ days; $100 \%$ had fever, including sudden fever $100 \%$, high fever $45,80 \%$ and $58.30 \%$ had chills; $60 \% \%$ pulse > 90 bpm; $12.50 \%$ with septic

${ }^{1}$ Viên Y hoc dư phòng Quân đội

²Bệnh viện Bệnh nhiệt đới Trung ương

${ }^{3}$ Bềnh viền Ouân y 103

Chịu trách nhiệm chính: Nguyễn Lan Hương

Email: nguyenlanhuong22290@gmail.com

Ngày nhận bài: 21.6.2021

Ngày phản biên khoa hoc: 19.8.2021

Ngày duyệt bài: 24.8.2021 shock; $61 \%$ had pneumonia; $16.90 \%$ had respiratory failure; WBC $>12 \mathrm{G} / \mathrm{L}$ was $43.80 \% ; \mathrm{Hb}<120 \mathrm{~g} / \mathrm{l}$ was $86.80 \%$; platelets < $150 \mathrm{G} / \mathrm{I}$ was $39.50 \%$; PT\% $<70 \%$ was $53.85 \%$; urea $>7.5 \mathrm{mmol} / \mathrm{L}$ was $47.06 \%$; creatinine $\geq 110 \mu \mathrm{mol} / \mathrm{L}$ was $28.21 \%$; total bilirubin $>$ $20 \mu \mathrm{mol} / \mathrm{l}$ was $47.83 \% ; 60 \%$ had PCT $>10 \mathrm{ng} / \mathrm{ml} ; 60 \%$ had CRP >100mg/L. Conclusion: Septicemia caused by $\mathrm{K}$. pneumoniae has a high rate of the path to infection from the respiratory and digestive tracts, multiple organ disorders, a high rate of septic shock and mortality rate.

Keywords: Septicemia; Klebsiella pneumoniae; Clinical, laboratory characteristics.

\section{I. ĐĂT VẤN ĐỀ}

Nhiễm khuẩn huyết là môtt bênh nhiễm khuẩn toàn thân nặng do sự xâm nhập liên tiếp vào máu của vi sinh vật gây bệnh và các sản phẩm đôc tố của chúng. Bệnh cảnh lâm sàng đa dạng, diễn biến thường nặng và không có chiều hướng tự khỏi nếu không được điều trị hoặc điều trị không đúng. Bênhh có thể gây ra tình trang sốc nhiễm khuẩn, suy đa phủ tạng[1]. Ngày nay, nhiễm khuẩn huyết vẫn là một nguyên nhân chính gây tử vong trên toàn thế giới [2].

Mầm bệnh gây nhiễm khuẩn huyết hàng đầu phải kể đển là nhóm vi khuẩn gram âm mà đặc biệt là K.pneumoniae[3]. K.pneumoniae đã trở thành nguyên nhân chính của các bệnh nhiễm khuẩn bệnh viện và và một yếu tố nguy cơ của các bệnh nhiếm khuẩn cộng đồng [4]. Hiện nay, nhiễm khuẩn huyết do $K$. pneumoniae có xu hướng ngày càng tăng, với đặc điểm tổn thương nhiều cơ quan, diễn biến lâm sàng đa dạng, tỷ lệ sốc nhiễm khuẩn và tử vong cao. Vì vầy, nhằm nâng cao hiệu quả chẩn đoán và điều trị NKH do K. pneumoniae, chúng tôi tiến hành đề tài: "Mô tả một số triệu chứng lâm sàng, cận lâm sàng ở bệnh nhân nhiễm khuẩn huyêt do K. pneumonia".

\section{II. ĐỐI TƯỢNG VÀ PHƯƠNG PHÁP NGHIÊN CỨU}

2.1. Đối tượng nghiêncứu.

- 48 bênh nhân NKH do K. pneumoniae, điều trị tại các khoa lâm sàng thuộc Bệnh viện Quân y 103 từ 01/2017 đến 6/2021.

- Tiêu chuẩn chẩn đoán: dựa trên khuyến cáo từ hội nghi đồng thuân giữa Hiệp họi hồi sức châu Âu và Hiệp hội y khoa lâm sàng (ESICM/ SCCM) về NKH (2016)[7]:

+Có sự thay đổi cấp tính điểm SOFA $\geq 2$ điểm do nhiễm khuẩn. 
+Kết quả cấy máu phân lập được K. pneumoniae.

+ Bênh nhân $\geq 18$ tuổi.

- Tiêu chuẩn loại trừ: Bệnh nhân có kết quả cấy máu dương tính với $\geq 2$ mầm bệnh.

\subsection{Phương pháp nghiên cứu.}

- Nghiên cứu mô tả, cắt ngang, kết hợp tiến cứu và hồi cứu.

- Thu thập số liệu qua bênh án lưu trữ, tất cả bệnh án nghiên cứu theo mầu biểuthống nhất.

- Nội dung nghiên cứu:

+ Đặc điểm chung: tuổi, giới, nguồn truyền nhiễm, bệnh lý nền, đường vào, các thủ thuật can thiệp xâm lấn, thời gian nằm viện, thời điểm cấy máu dương tính, điểm SOFA, tỷ lệ tử vong.

+ Triệu chứng lâm sàng: đặc điểm và tính chất sốt; tình trạng ý thức; tổn thương hệ tuần hoàn (mạch, huyết áp, sốc...); tổn thương hệ hô hấp (viêm phổi, suy hô hâp...); tổn thương hệ tiêu hóa (rối loạn tiêu hóa, đau bụng, ...); tổn thương hệ tiết niệu (thiểu niệu, vô niệu...).

+ Các chỉ số cận lâm sàng: số lượng hồng câu $(\mathrm{T} / \mathrm{l})$, hemoglobin $(\mathrm{g} / \mathrm{l})$; số lượng bạch câu $(\mathrm{G} / \mathrm{l})$, phần trăm neutrophil; tiểu cầu $(\mathrm{G} / \mathrm{l})$; tỷ lệ prothrombin (\%); enzym AST, ALT (U/l); bilirubin toàn phần $(\mu \mathrm{mol} / \mathrm{l})$; ure máu $(\mathrm{mmol} / \mathrm{l})$; creatinin máu $(\mu \mathrm{mol} / \mathrm{l}) ; \quad$ CRP $(\mathrm{mmol} / \mathrm{L})$; procalcitonin $(\mathrm{ng} / \mathrm{ml})$.

- Kết quả thu được xử lý trên phần mềm SPSS phiên bản 22.0.

\section{KẾT QUẢ NGHIÊN CỨU}

Trong thời gian từ 01/2017 tới 06/2021, chúng tôi thu được số liệu của 48 BN đủ tiêu chuẩn chọn vào nghiên cứu với các đặc điểm sau:

Bảng 3.1: Đặc điềm chung của nhóm bệnh nhân nghiền cứu

\begin{tabular}{|c|c|c|}
\hline Đặc điểm & $\begin{array}{c}\text { Số bệnh } \\
\text { nhẩn }\end{array}$ & $\begin{array}{c}\text { Tỷ lệ } \\
\text { \% }\end{array}$ \\
\hline Tuối trung bình & \multicolumn{2}{|c|}{$62,67 \pm 12,66$} \\
\hline Trên 60 tuối & $22 / 48$ & 45,83 \\
\hline Nam giới & $37 / 48$ & 77,08 \\
\hline Có bệnh nền & $35 / 48$ & 75,90 \\
\hline Nhiêm trùng bệnh viện & $6 / 48$ & 10,40 \\
\hline Dường vào hồ hấp & $17 / 41$ & 41,46 \\
\hline Đường vào tiêu hóa & $16 / 41$ & 39,20 \\
\hline Có can thiệp thủ thuật & $13 / 48$ & 27,08 \\
\hline $\begin{array}{c}\text { Thời gian nằm viện } \\
\text { trung bình }\end{array}$ & \multicolumn{2}{|c|}{$16,31 \pm 9,5$ ngày } \\
\hline
\end{tabular}

Tuối trung bình nghiên cứu $62,67 \pm 12,66$; nhóm tuổi > 60 chiếm tỷ lê $45,83 \%$; đường vào đường hô hấp và tiêu hóa lần lượt 41,46 và $39,20 \%$.

\section{Bảng 3.2: Các triệu chứng lâm sàng}

\begin{tabular}{|c|c|c|c|c|c|c|}
\hline \multicolumn{2}{|c|}{ Triệu chứng } & Số BN & Tỷ lệ \% & Triệu chứng & Số BN & Tỷ lệ \% \\
\hline \multirow{2}{*}{ Sốt } & Đột ngột & $48 / 48$ & 100 & Rối loạn ý thức & $4 / 48$ & 8,89 \\
\hline & Sốt cao & $\frac{22 / 48}{28 / 48}$ & $\begin{array}{l}45,90 \\
58,30\end{array}$ & Thiểu niệu, vô niệu & $2 / 44$ & 4,50 \\
\hline \multicolumn{2}{|r|}{ Viêm phô̂i } & $\begin{array}{l}28 / 48 \\
31 / 48\end{array}$ & $\begin{array}{l}58,30 \\
64,60\end{array}$ & Sốc nhiềm khuấn & $6 / 48$ & 12,50 \\
\hline \multirow{2}{*}{\multicolumn{2}{|c|}{$\begin{array}{l}\text { Suy hô hâp } \\
\text { SOFA max }\end{array}$}} & $10 / 48$ & 20,80 & Tứ vong do SNK & $5 / 6$ & 83,30 \\
\hline & & \multicolumn{2}{|c|}{$3,90 \pm 2,23$} & Kết cục tử vong & $9 / 48$ & 18,80 \\
\hline
\end{tabular}

Viêm phổi $64,60 \%$; suy hô hấp cần can thiệp $20,80 \%$. Tỷ lẹ sốc nhiễm khuấn và tử vong $12,50 \%$ và $18,80 \%$.

Bảng 3.3. Các xét nghiệm cận lâm sàng

\begin{tabular}{|c|c|c|c|c|c|}
\hline Chỉ số cận lâm sàng & Số BN & Tỷ lệ \% & Chỉ số cận lâm sàng & Số BN & Tỷ lệ \% \\
\hline $\mathrm{Hb}<120 \mathrm{~g} / \mathrm{l}$ & $23 / 38$ & 56,80 & Ure $>7,5 \mathrm{mmol} / \mathrm{l}$ & $16 / 34$ & 47,06 \\
\hline Bạch cầu $>12 \mathrm{G} / \mathrm{l}$ & $21 / 48$ & 43,80 & Creatinin $>110 \mu \mathrm{mol} / \mathrm{l}$ & $11 / 39$ & 28,21 \\
\hline Bạch cấu neutrophil $>75 \%$ & $41 / 48$ & 85,42 & AST $>40 \mathrm{U} / \mathrm{l}$ & $25 / 32$ & 78,12 \\
\hline Tiếu câu $<150 \mathrm{G} / \mathrm{l}$ & $15 / 38$ & 39,50 & ALT $>40 \mathrm{U} / \mathrm{l}$ & $20 / 31$ & 64,52 \\
\hline Tỷ lệ Prothrombin $<70 \%$ & $7 / 13$ & 53,85 & Albumin $<35 \mathrm{~g} / \mathrm{l}$ & $21 / 28$ & 75 \\
\hline $\mathrm{CRP}>100 \mathrm{mg} / \mathrm{l}$ & $15 / 25$ & 60,00 & Bilirubin toàn phần $>20 \mu \mathrm{mol} / \mathrm{l}$ & $12 / 23$ & 52,17 \\
\hline $\mathrm{PCT}>10 \mathrm{ng} / \mathrm{ml}$ & $18 / 30$ & 60,00 & Lactat $>2 \mathrm{mmol} / \mathrm{l}$ & $5 / 11$ & 45,45 \\
\hline
\end{tabular}

Tăng bạch câuu (>12G/l) 43,80\%; giảm tiếu cầu 39,50\%. CRP > $100 \mathrm{mg} / \mathrm{l}$ và PCT > $10 \mathrm{ng} / \mathrm{ml}$ đều chiếm tỷ lệ 60,0\%.

\section{BÀN LUẬN}

4.1. Một số đặc điểm chung của nhóm bệnh nhân nghiêncứu. Trong nghiên cứu của chúng tôi, tuổi trung bình của bệnh nhân là $62,67 \pm 12,66$ tuổi; trong đó 45,83\% trên >60 tuổi; nam giới chiếm 77,08\%; có bệnh lý nền là
72,9\%; nhiễm trùng bệnh viện chiếm 10,4\%; đường vào gây nhiễm khuẩn huyết là đường hô hấp $(41,46 \%)$ và tiêu hóa $(39,2 \%)$; không rõ đường vào $(24,6 \%) ; 27,08 \%$ bệnh nhân cần can thiệp thủ thuật xâm lấn; thời gian nằm viện

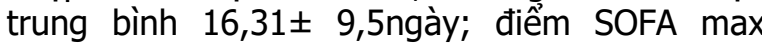




\section{3,90土2,23điểm.}

Qua so sánh chúng tôi thấy rằng tuổi trung bình của các bệnh nhân trong nghiên cứu của chúng tôi có sự tương đồng so với trong nghiên cứu của các tác giả Nguyễn Thi Phương (2016)[5], Trịnh Văn Sơn (2021)[6], Trần Nhật Minh (2019)[7]. Tuy nhiên, có sự chênh lệch về đối tượng trên 60 tuổi, lý giải về điều này là do sự lựa chọn đối tượng nghiên cứu của chúng tôi khác các tác giả trên.

Về sự phân bố của bệnh theo giới, trong nghiên cứu của chúng tôi tỷ lệ bệnh nhân nam cao hơn bệnh nhân nữ 3,36 lần. Tác giả Nguyễn Thị Phương (2016) nam so nữ 2,27 lần[5]. Tác giả Trân Nhật Minh (2019) nam giới chiếm 61,2\%[7]. Theo tác giả Harada S (2019) thì nam giới chiếm 62,1\%[8]. Qua phân tích chúng tôi thấy kết quả nghiên cứu của chúng tôi có sự tương đồng với tác giả kể trên.

Về giới tính, theo nhiều tác giả, nam giới mắc nhiều và tiên lượng nặng hơn có thể do ảnh hưởng của hormon sinh dục trên bệnh lý này, do tình trang nhiễm khuẩn của nam nhiều và tỷ lệ can thiệp thủ thuâtt nhiều hơn so với nữ giới.Cụ thể, NC của Martin K Angele và cs. (2014) thấy rằng trong khi các hormon sinh dục nam như androgen gây ức chế miễn dịch qua trung gian tế bào, thì ngược lại, các hormon sinh dục nữ lại có tác dụng tăng cường miễn dịch, từ đó có tác dụng bảo vệ cơ thể trong NKH.

Bệnh lý nền trong nghiên cứu của chúng tôi tương đồng với kết quả trong nghiên cứu của các tác giả khác, điều này càng củng cố rằng bệnh lý nền trong nhiễm khuẩn huyết do $\mathrm{K}$. pneumoniae thường gặp là tim mạch, đái tháo đường, xơ gan, lạm dụng/nghiện rượu, ung thư.

Bên cạnh đó, đường vào của nhiễm khuẩn huyết do K. pneumoniae vẫn chủ yếu từ hô hấp và tiêu hóa. Vì vậy cần đặc biệt phòng tránh nhiễm khuẩn tại các cơ quan này, đặc biệt là nhiễm khuẩn do K. pneumoniae, có thể dẫn đến nhiễm khuẩn huyết.

4.2. Đắc điểm lâm sàng. Nhiễm khuẩn huyết do K K pneumoniae có bệnh cảnh nhiễm trùng, nhiễm độc nặng tương tự như nhiễm khuẩn huyết do vi khuẩn Gram âm khác. 100\% bệnh nhân có sốt, với đặc điểm sốt đột ngột $100 \%$, sốtcao $45,80 \%$ và $58,30 \%$ có cơn rét run. Tác giả Nguyễn Thị Phương (2016) nghiên cứu trên 98 bênh nhân NKH do K. pneumoniae thì có tới $98 \%$ có biểu hiện sốt, sốt đột ngột $(61,5 \%)$, sốt cao $(63,3 \% \%)$, liên tục $(11,5 \%)$, rét run $(57,3)[5]$. Kết quả trong nghiên cứu của chúng tôi tương đồng; lý giải điều này chúng tôi chỉ xét nhiệt độ khi bệnh nhân cấy máu. Kết quả nghiên cứu của chúng tôi góp phần củng cố thêm vào nét đặc trưng của triệu chứng sốt trong nhiễm khuẩn huyết là sốt cao, liên tục, trong ngày có nhiều cơn rét run.

Bệnh cảnh nhiễm khuẩn huyết sẽ ảnh hưởng đến toàn thân, tổn thương đa cơ quan. Trong nghiên cứu của chúng tôi, nhiều cơ quan tổn thương như tim mạch $(60 \%$ có mạch nhanh; sốc $12,5 \%)$, thần kinh ( $8,89 \%$ có rối loạn ý thức), hô hấp (suy hô hấp 20,80\%; viêm phổi $64,60 \%$ ), tiết niệu (thiểu niệu, vô niệu 4,50\%). Có 18,8\% $\mathrm{BN}$ tử vong.Trong nghiên cứu của chúng tôi tỷ lệ sốc nhiễm khuẩn (12,50\%), sốc nhiễm khuẩn có tử vong là $83,3 \%$. Hệ hô hấp là cơ quan gây bênh hàng đầu của $K$. pneumoniae với bênh cảnh lâm sàng rất đa dạng. Các triệu chứng viêm phổi chiếm $64,6 \%$ suy hô hấp chiếm $20,8 \%$, tràn dich màng phổi là $16,7 \%$ trong nghiên cứu của chúng tôi. Tác giả Nguyễn Thị Phương (2016) ghi nhận viêm phổi $(32,2 \%)$, suy hô hấp $(14,9 \%)$, tràn dịch màng phổi $(2,3 \%)$ [5]. Tổn thương phổi trên hình ảnh $X Q$ tim phổi trong nghiên cứu của chúng tôi viêm phổi thùy chiếm tỷ lê cao nhất $46,7 \%$, rất phù hợp căn nguyên nhiếm khuẩn huyết do K. pneumoniae

4.3. Đắc điểm cận lâm sàng. Xét nghiệm cận lâm sàng ở bệnh nhân nhiễm khuẩn huyết do K. pneumoniae có biến đổi cả về huyết học, sinh hóa và vi sinh, cụ thể tỷ lệ bạch cầu $\geq 12$ G/L là 43,80\%; neutrophil> 75\% chiếm $85,42 \%$; $56,8 \%$ BN có hemoglobin < $120 \mathrm{~g} / \mathrm{L}$; tiểu câu < $150 \mathrm{G} / \mathrm{L}$ có $39,5 \%$; tỷ lệ prothrombin < $70 \%$ là $53,85 \%$.Về sinh hóa: $16 / 34 \mathrm{BN}$ ure $\geq 7,5 \mathrm{mmol} / \mathrm{L}$ tương đương 47,06\%; creatinin $>110 \mu \mathrm{mol} / \mathrm{L}$ là 28,21\%;ALT > 40 IU/L chiếm 78,12\%; bilirubin $>20 \mu \mathrm{mol} / \mathrm{L}$ chiếm 52,17\%; lactat > $2 \mathrm{mmol} / \mathrm{L}$ $60 \%$. Hơn nữa, bênh nhân có markers viêm tăng rất cao: $60 \%$ bệnh nhân cóCRP $>100 \mathrm{mg} / \mathrm{L}$ và $60 \%$ có $\mathrm{PCT}>10 \mathrm{ng} / \mathrm{ml}$. Xét nghiệm chức năng cơ quan trong nghiên cứu của chúng tôi có nhiều điểm tương đồng với các nghiên cứu trước đây như tỷ lệ bệnh nhân có tình trạng thiếu máu, giảm tiểu cầu, rối loạn chức năng gan thận tương đối cao. Về marker viêm, kết quả của chúng tôi cũng như các tác giả khácđều phản ánh đáp ứng viêm mạnh mẽ của cơ thể trong NKH do K. pneumoniae. Theo tác giả Nguyễn Thi Phương (2016) ghi nhận bạch cầu tăng trên $12 \mathrm{G} / \mathrm{L}$ chiếm $65 \%$, CRP $>100 \mathrm{mg} / \mathrm{L}$ có $66,6 \%$ và PCT >10ng/mL chiếm 53,7\%[5].

\section{KẾT LUÂN}

-Lâm sàng: Nhiễm khuẩn huyết do $\mathrm{K}$. 
pneumoniae thường gặp ở người cao tuổi, nam giới có tỷ lệ mắc cao, trên các bệnh nhân có bệnh lý nền, thời gian nằm viện dài, đường vào thường là đường hô hấp và tiêu hóa. Bệnh cảnh lâm sàng nổi bật tổn thương nhiều cơ quan như tim mạch, thần kinh, hô hấp, tiết niệu, sốc nhiêm khuẩn và tử vong.

-Cận lâm sàng: Bạch cầu $\geq 12 \mathrm{G} / \mathrm{L}$ là 43,80\%; neutrophile >75\% chiếm 85,42\%; $56,8 \%$ BN có hemoglobin $<120 \mathrm{~g} / \mathrm{L}$; creatinin > $110 \mu \mathrm{mol} / \mathrm{L}$ là $47,06 \%$; lactat $>2 \mathrm{mmol} / \mathrm{L} 60 \%$. Các marker viêm tăng cao (bạch cầu $\geq 12 \mathrm{G} / \mathrm{L}$ chiếm 45,83\%; CRP >100mg/L: $60 \%$ và PCT $>10 \mathrm{ng} / \mathrm{ml}$ chiếm 60\%;).

\section{TÀI LIÊU THAM KHẢO}

1. Bộ môn Truyên nhiễm - Học viện Quân y (2008). Nhiễm khuẩn huyết, Nhà xuất bản y học.

2. Salomao R (2019). Sepsis Eveloping concepts and challeges.

3. Gustinetti G., Mikulska M. (2016). Bloodstream infections in neutropenic cancer patients: a practical update. Virulence, 7(3), 280-297.

4. Wang G., Zhao G., Chao X., et al. (2020). The characteristic of virulence, biofilm and antibiotic resistance of Klebsiella pneumoniae. International Journal of Environmental Research and Public Health, 17(17), 6278.

5. Nguyễn Thị Phương(2016). Nghiên cứu đặc điểm lâm sàng, cân lâm sàng và yếu tố tiên lượng nặng ở bệnh nhẩn NKH do Klebsiella, Luận văn Thạc sĩ y học, Học viện Quân y.

6. Trịnh Văn Sơn(2021). Nghiên cứu tính kháng kháng sinh của Klebsiella và E.coli, Luân án Tiến sĩ y học, Viện nghiên cứu khoa học y dược lẩm sàng 108.

7. Trân Nhật Minh(2019). Phân tích đặc điểm lâm sàng, vi sinh và phác đồ điều trị nhiếm khuẩn huyết do K. pneumoniae tại khoa hồi sức tích cực bệnh viện Bạch Mai, Luận văn Thạc sĩ Dược học, Đại học dược Hà Nội.

8. Harada S A. K., Yamamoto S, (2019). Clinical and Molecular Characteristics of Klebsiella pneumoniae Isolates Causing Bloodstream Infections in Japan: Occurrence of Hypervirulent Infections in Health Care. J Clin Microbiol.

\section{KẾT QUẢ ĐIỀU TRỊ UNG THƯ SÀN MIÊNNG GIAI ĐOẠN cT1-2NOMO TẠI BỆNH VIỂN K}

\section{TÓM TẮT.}

Mục tiêu: Đánh giá tình trang tái phát, thời gian sống thêm và phân tích một số yếu tố liên quan trên bệnh nhân (BN) ung thư sàn miệng giai đoạn cT12NOMO được điêu trị tại Bệnh viện K. Đối tượng nghiên cứu: Bao gôm 65 BN ung thư sàn miệng giai đoạn cT1-2NOMO được chẩn đoán và điều trị tại Bệnh viện $\mathrm{K}$ trong thời gian từ $01 / 2015$ đến $12 / 2019$. Phương pháp nghiên cứu: Nghiên cứu mô tả cắt ngang. Kết quả: Trong $65 \mathrm{BN}$ nghiên cứu, đa số $\leq 60$ tuổi $(73,8 \%)$; tỷ lệ nam/nữ: 8,3/1;32,3\% BN di căn hạch tiềm ẩn. Có $21 B N$ tái phát sau điều trị $(32,3 \%)$, vị trí hay gặp là hạch cổ $(57,1 \%)$, đa số xảy ra trong 24 tháng đầu $(71,4 \%)$. Kích thước u và di căn hạch tiềm ẩn có liên quan đến tỷ lệ tái phát $(p<0,05)$. Tỵ lệ DFS và OS 5 năm lần lượt là $62,3 \%$ và $74 \%$, thời gian DFS và OS trung bình lần lượt là 45,08 và 52,03 tháng. Các yếu tố ảnh hưởng đển DFS gốm kích thước $u(p=0,03)$, di căn hạch $(p<0,001)$ và giai đoan bệnh sau phầu thuật $(p<0,001)$. Các yếu tố ảnh hưởng đến OS gồm kích thước u $(p=0,037)$, di căn hạch

\footnotetext{
${ }^{1}$ Trường Đại học Y Hà Nội,

${ }^{2}$ Bênh viên $K$

Chịu trách nhiệm chính: Nguyễn Văn Trọng

Email: vantrong.hmu@gmail.com

Ngày nhận bài: 22.6.2021

Ngày phản biện khoa học: 19.8.2021

Ngày duyệt bài: 24.8.2021
}

\author{
Nguyễn Văn Trọng1, Ngô Quốc Duy², \\ Lê Chính Đại ${ }^{1}$, Lê Văn Quảng ${ }^{1,2}$
}

$(p=0,005)$ và giai đoạn bệnh sau phẫu thuật $(p<0,001)$. Kết luận: Tái phát sau điều trị UT sàn miệng thường gặp tại hạch cổ và tại chố. Kích thước u và di căn hạch có liên quan đến tình trạng tái phất. Kích thước ù, di căn hạch và giai đoạn bệnh sau phẫu thuật ảnh hưởng xấu đến sống thêm toàn bộ và không bệnh.

Tư khóa: ung thư sàn miệng, T1-2NOM0, tái phát, sống thêm

\section{SUMMARY \\ RESULTS OF TREATMENT FOR CT1-2NOMO CARCINOMAS OF THE FLOOR OF MOUTH}

Objectives: This study was conducted to report the recurrence rate, the survival rate in mouth floor cancer patients staged cT1-2NOMO and analyze the prognostic factors associated. Patients and methods: A retrospective, descriptive study on 65 patients with CT1-2NOM0 floor of mouth cancer were treated in K hospital from $01 / 2015$ to $12 / 2019$. Results: Majority were under 60 years old $(73,8 \%)$; male/female ratio: $8,3 / 1 ; 34$ patients were staged T1 (52,3\%); occult lymph node metastasis rate: $32,3 \%$. Recurrences were diagnosed in 21 patients $(32,3 \%)$, the nodal and local-nodal recurrence rate were $57,1 \%$ and $23,8 \%$, respectively. Tumor stage and occult lymph node metastasis were statistically associated with the recurrence $(p=0,034$ and $p=0,001$, respectively). The 5 -year DFS and OS rates were $62,3 \%$ and $74 \%$, respectively. The mean DFS and OS 